\title{
Factors influencing the alignment of accounting information systems of accepted manufacturing firms in Tehran Stock Exchange
}

\author{
Fazel Tamoradi*
}

Department of Management and Accounting, Ramhormoz Branch, Islamic Azad University, Tehran, Iran

\begin{tabular}{l}
\hline C H R O N I C L E \\
\hline Article history: \\
Received October 28, 2013 \\
Received in revised format \\
25 November 2013 \\
Accepted 19 January 2014 \\
Available online \\
January 232014 \\
\hline Keywords: \\
Accounting information system \\
Management accounting system \\
alignment \\
Fit \\
Organizational information \\
processing theory \\
Developing countries \\
\hline
\end{tabular}

A B S T R A C T

\begin{abstract}
The primary objective of this paper is to detect factors influencing the alignment of accounting information systems for firms in manufacturing sector listed on Tehran Stock Exchange. The concept of alignment has been investigated for many years, and strategic alignment plays essential role in increasing company performance. This paper investigates different levels of alignment and studies the factors, which influence alignment. More specifically, the work concentrates on the alignment between the requirements for accounting information (AIS requirements) and the capacity of accounting systems (AIS capacity) to build the information, in the specific context of manufacturing in Iran. The research sample consists of 216 companies over the period 2011-2007. The fit between these two sets was explored based on the moderation method and evidences indicate that AIS alignment in some firms was high. In addition, the relationship between the dependent variable and independent variables through multiple regressions yields a positive relationship between these variables.
\end{abstract}

(C) 2014 Growing Science Ltd. All rights reserved.

\section{Introduction}

There are many studies emphasized on development a fit between business strategy and information technology (IT) strategy. Yet many business organizations attempt to achieve alignment and there are literally few studies of alignment and the factors influencing on the alignment in organizations (Breen $\&$ Sciulli, 2002). A brief review on accounting and information systems literature disclose that some studies have studied the alignment between contingency factors and accounting information systems (AIS) design (Ismail \& King, 2007; Chong \& Chong, 1997; Chenhall \& Langfield-Smith, 1998; Mia \& Clarke 1999; Adekoya et al., 2005) or the alignment between contingency and IT sophistication (Ismail \& King, 2007; Weill \& Olson, 1989; Henderson \& Venkatraman, 1993; Bergeron et al., 2001; Ortiz de Guinea et al., 2005; Zarowin, 1998) specifically among large business organizations. Chang and Jevons Lee (1992) discussed that effects from these factors could be computed by the degree of a

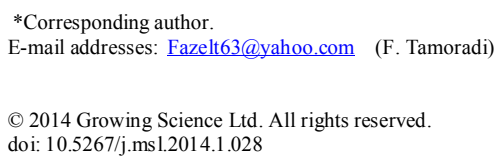


organization's information requirements, which could be available by firms' investigating in AIC systems (Bolon, 1998).

This paper presents a study to fill this gap by investigating various factors influencing AIS alignment in the specific context of Iranian manufacturing firms. This objective is achieved by clustering the information based on alignment between accounting information requirements (represented by AIS requirements) and accounting information system processing capacity (represented by AIS capacity). The alignment groups are then examined against potential impact factors to determine their relationships with AIS alignment. The study concentrates on AIS alignment because AIS, which covers both the financial and managerial characteristics of accounting information, is an essential part of modern information systems within SMEs (Mitchell et al., 2000; Ismail \& King, 2007). This exploratory study also tries to detect fruitful areas of future research in the areas of accounting and information systems.

We first present a comprehensive review on existing literature on AIS and information system development in small and medium enterprises (SMEs). The study demonstrates that there were rather contradictory results about AIS design in SMEs and there were ambiguous achievements about the strategic use of information technology (IT) in SMEs, which somehow justifies more investigation into the fit of AIS necessities with AIS capacity. We first explain the development of the research model, involving six hypotheses on six variables identified as likely to be related with alignment, and describe the method for computing alignment. In the next section, details of the sample applied are described. Then cluster analysis is implemented to detect two alignment groups: those with AIS alignment and those, which are not aligned. These two different groups are applied to examine the research hypotheses. In the next section, the results are discussed, the theoretical and practical implications are described and the limitations of the study are identified.

\section{Literature review}

The idea of alignment used in this research was first developed by Galbraith's (1973) information processing (IP) theory (Ismail \& King, 2007), which can be classified as contingency theory (Bolon 1998). IP theory postulates that the IP capacity of a particular firm must match its information requirements, if IP capacity is to have a substantial impact on performance (Galbraith 1973). According to Ismail and King (2007), the theory assumes that an organization is "... a complex system whose primary problem of relating to its environment is the acquisition and utilisation of information" (Bolon 1998, p.212) - the bigger the uncertainty, the bigger the amount of information that needs to be processed to reach a given level of performance. Many firms would thus respond to the increasing information demand by increasing or reducing their IP capacity (Galbraith 1973). While IP theory was originally developed in the context of large and complex organizations, several studies have successfully implemented this concept of fit in the context of smaller firms (e.g., El Luoadi, 1998; Ismail \& King 2005; Khazanchi, 2005). This study applies IP theory to investigate the fit or alignment between AIS requirements and AIS capacity, and to detect factors, which might be associated with an SME's level of AIS alignment. This approach is also consistent with Van de Ven and Drazin's (1985) suggestion that an organizational outcome is the consequence of fit between two or more factors. The following paragraphs discuss extant literature relating to AIS and information system development in SMEs.

Mitchell et al. (2000) argued that accounting information could assist SMEs manage short-term problems in various areas such as cost accounting, expenditure and cash flow by providing necessary information to support monitoring and control. Nevertheless, the existing literature provides insufficient evidence of AIS development within SMEs. Many studies imply that SMEs had little management information and poor control, and that decision-making is mostly ad hoc (Marriot \& Marriot 2000). McMahon (2001), for instance, recommended that financial accounting had remained 
the principle source of information for internal management in SMEs. Marriot and Marriot (2000) also recommended that financial awareness among managers of SMEs varies substantially and that the implementation of computers for the preparation of management accounting information is not at its full potential.

Many studies have also been performed to give insight on how IT has been implemented to support information requirements in SMEs (e.g. El Louadi, 1998; Temtime et al., 2003; Ismail \& King, 2005). The results from the past studies indicate that IT adoption had grown tremendously within SMEs. Yet there are significant evidences to recommend that very few of the resulting systems have had any significant impact on the way management makes decisions (Temtime et al., 2003). Fuller (1996) discussed that the key issue of the lack of strategic IT usage in SMEs was associated with the relatively poor fit between what the software tools were offering and what was required, with neither the users nor the suppliers being in a good position to communicate with each other. The situation becomes more important within SMEs because they did not have sufficient experienced internal accounting and IT expertise and support (Mitchell et al., 2000). The consequent lack of expertise restricts information understanding, IT specifications and selection policies, and it inevitably leads SMEs to implement or buy an information system, which is inadequate to the firms' needs (Ravarini et al., 2002).

In summary, IT success has been examined and discussed in the SME context and some recent studies indicate that IT alignment is important for SMEs. However, there are few studies focused on issues surrounding the alignment of information requirements and information system processing capacity in SMEs including factors influencing this alignment. Thus, this study aimed to provide further evidence about this issue, with emphasis on accounting information, and the factors associated with an SME's level of AIS alignment.

\section{Research hypothesis}

According to Huber (1990, p.65), “... use of advanced IT leads to more available and more quickly retrieved information, including external information, internal information, and previously encountered information, and thus leads to increased information accessibility". Firms with extensive resources may gain a competitive edge by deploying IT in support of or to strengthen their business (King et al., 1989). Chan et al. (1997) and Hussin et al. (2002) found that an appropriate level of IT sophistication was associated with the capability to align IT strategy and business strategy. Hence, it is expected that firms with more sophisticated IT will have a higher degree of AIS alignment. This study is an adaptation of earlier work accomplished by Ismail and King (2007).

$\mathrm{H}_{1}$ : Firms that have more sophisticated IT will have a higher degree of AIS alignment than those firms with less sophisticated IT.

In the context of SMEs, an owner/manager's IT knowledge can determine the success or failure of computerization projects because they play a dominant role in an SME's business decisions (Hussin et al., 2002). Most often, the owner/manager of the firm is the only person who fully understands the objectives and directions of the firm (Thong 1999). Therefore, owners/managers who are aware of existing and new technologies could be capable of choosing the right software for their firms (Hussin et al. 2002; Ismail \& King, 2007). In the context of AIS, owners/managers with both IT and accounting knowledge are in a better position than those without this knowledge. It is because they are able to understand the firm's AIS requirements and then use their IT knowledge to determine the IT deployment, which fits the firm's information needs. Therefore, it is expected that in organizations wherein the owner/manager possesses enough IT and accounting knowledge, there will be a higher degree of AIS alignment. 
$\mathrm{H}_{2}$ : Organizations with owner/managers having high levels of IT and accounting knowledge will have a higher degree of AIS alignment than those with owner/managers having low levels of IT and accounting knowledge.

In addition to knowledge, an owner/manager's commitment also plays essential role in the effectiveness of information system implementation in SMEs (Thong \& Yap, 1995; Igbaria et al., 1997). Due to their dominant roles, an owners/managers commitment can bring IT into alignment with the firm's objectives and strategies (Jarvenpaa \& Ives 1991; Ismail \& King, 2007).

$\mathrm{H}_{3}$ : Firms with owner/managers having high levels of commitment will have a higher degree of AIS alignment than those firms with owner/managers having low levels of commitment.

Generally, big corporations are more likely to adopt or make extensive implementation of IT (Winston \& Dologite, 1999; Ismail \& King, 2007). Computerization projects are also less likely to succeed in smaller organizations, when compared with larger ones, because of their limited resources and lack of formalization of information systems structure (Thong 2001). Most small firms do not have available funds to invest in IT and do not have the support to help them choose the right technology. Therefore, it is expected that larger firms are more likely to achieve higher degrees of AIS alignment than smaller firms are (Ismail \& King, 2007).

$\mathrm{H}_{4}$ : Larger firms will have a higher degree of AIS alignment than smaller firms.

\subsection{AIS alignment}

The idea of alignment or fit has been debated in the literature and a number of approaches have been developed to operationalize the concept (Ismail \& King, 2007). Venkatraman (1989) provided six various perspectives. Different approaches need various mathematical models and have different theoretical implications (Bergeron et al., 2001). A number of studies in both the accounting and information system literatures have used the moderation and matching approaches. Other approaches are still in their preliminary stages and thus need further development (Cragg et al., 2002). This study modelled fit using the moderation approach because of the weight of evidence in favor of this approach (e.g., Chan et al., 1997; Cragg et al., 2002; Hussin et al., 2002). The moderation perspective assumes that alignment reflects synergy. Therefore, alignment is calculated as the interaction between two measures, which, in this case, are AIS requirements and AIS capacity. For instance, AIS capacity has a different impact on a high value for the AIS requirements compared with a low value. The bigger the value of AIS capacity, the higher the effect of AIS requirements on performance (Ismail \& King 2005).

In terms of measurement, both AIS requirements and AIS capacity were measured using questions that drew heavily on the instrument developed by Chenhall \& Morris (1986). While other instruments are available, their concentration is more on the practice of formal accounting techniques. Since many SMEs acquire information via informal means (Ismail \& King, 2007; Perren \& Grant, 2000; Gul, 1991; Gul \& Chia, 1994), asking objective questions seemed to be irrelevant in the context of SMEs. Other instruments are also restricted to the characteristics of financial accounting information, which is not the only focus of this study.

\subsection{IT sophistication}

IT sophistication is considered as a multi-dimensional variable and many studies have measured the item differently. Raymond \& Pare (1992) are among the first who developed the most comprehensive measure of IT sophistication, which includes all characteristics associated with technological, informational, functional, and managerial sophistication. They defined IT sophistication as “... a construct which refers to the nature, complexity and interdependence of IT usage and management in an organization" (Raymond \& Pare 1992, p.7). Technological sophistication gives the number or diversity of IT applied, while informational sophistication is characterized by the nature of its application characteristics. This study adopted only two dimensions of IT sophistication 
(technological and informational sophistication) (Ismail \& King, 2007) to represent IT sophistication. Functional and managerial sophistication are considered less relevant because most SMEs do not have IT functions (Thong 2001). Besides, Hussin et al. (2002) investigated the effect of three dimensions of IT sophistication on IT alignment. They reported a substantial relationship between IT alignment and technological sophistication but not with functional and managerial sophistication.

\subsection{Owner/manager IT and accounting knowledge}

This study measured owner/manager IT knowledge based on a list of seven applications commonly found in SMEs. Using a five-point scale $(1=$ no knowledge; $5=$ extensive knowledge $)$, the respondents were requested to show the extent to which they were familiar with word processing, spreadsheet, database, accounting, e-mail, Internet and computer-assisted production management applications. Using the same scale, respondents were then requested to explain their knowledge level relating to financial and managerial accounting techniques.

\subsection{Owner/manager commitment}

This study adopted a similar instrument used by Hussin et al. (2002) and Ismail and King (2007) to measure owner/manager participation in information system implementation. The instrument, which was originally developed by Jarvenpaa and Ives (1991) was tested and validated by Hussin et al. (2002). Using a five-point scale $(1=$ no participation; $5=$ high participation), respondents were requested to indicate their level of participation in the following five areas: definition of needs (information requirements), selection of hardware and software, implementation of systems, systems maintenance and problem solving, and planning for future IT deployment.

\section{Research method}

The primary concentration of this study was on AIS alignment in SMEs. This was further restricted to manufacturing organizations because the manufacturing sector is able to provide a range of levels of IT sophistication (Cragg et al., 2002; Ismail \& King, 2007) achieve this, a mail questionnaire survey carried out from August to October 2011 was used to gather data. The questionnaires were addressed to the Managing Directors (MD) of the firms. MDs were chosen to be the respondents of this study because they were more likely to have valid perceptions of the AIS design and IT approach adopted by the firms. This is because the MD commonly makes most key decisions and is perhaps the only person who can harness IT to achieve the firm's objectives and strategy (Jarvenpaa \& Ives, 1991). A total of 230 firms eventually responded to the survey after a period of ten weeks and two follow-up reminders, which were sent a week and three weeks after the initial letter. However, only 214 firms answered both the AIS requirements and AIS capacity items and were thus usable for subsequent analyses, resulting in about a $29 \%$ response rate.

\section{Results}

The main objective of this paper is to examine the factors that influence AIS alignment. To achieve this, in the next section the alignment between AIS requirements and AIS capacity will be determined using the moderation approach. Then, using cluster analysis, firms will be grouped according to their degree of AIS alignment.

\subsection{AIS alignment}

Some moderation technique for measuring fit was initially explored to compute the alignment between AIS requirements and AIS capacity. For each firm and each information characteristic, the AIS alignment was computed by multiplying the rating of an AIS requirement item with the rating of the corresponding AIS capacity item (See Ismail \& King, 2007 for more details). 


\section{Table 1}

Mean rating for AIS alignment items

\begin{tabular}{lcc}
\hline Information characteristics & AIS alignment & SD \\
\hline Frequency of reporting & 14.54 & 5.5 \\
Summary reports-organization & 13.56 & 5.90 \\
Summary reports-sections & 14.23 & 5.66 \\
Sectional reports & 12.90 & 4.45 \\
Speed of reporting & 13.80 & 5.23 \\
Temporal reports & 14.10 & 5.87 \\
Future events & 12.30 & 5.95 \\
Immediate reporting & 11.95 & 5.68 \\
Non-financial (production) & 11.10 & 5.82 \\
Automatic receipt & 11.02 & 5.44 \\
Organizational effect & 11.00 & 5.33 \\
Precise targets & 10.15 & 5.70 \\
Non-financial (market) & 9.20 & 5.90 \\
Effects of events on functions & 9.30 & 5.85 \\
Non-economic information & 9.02 & 5.08 \\
What-if analysis & 8.45 & 5.05 \\
\hline
\end{tabular}

\subsection{Hypothesis testing of variables influencing AIS alignment}

When we have determined two groups of firms with various levels of AIS alignment, we examine the variables posited in section 3 to be associated with AIS alignment: IT sophistication; owner/manager knowledge; owner/manager commitment; external expertise; internal expertise; and firm size. To test the hypotheses, the aligned and not-aligned groups of firms were compared for each variable.

\subsubsection{IT sophistication and AIS alignment}

This study adopted technological sophistication and informational sophistication from Raymond \& Pare's (1992) and Ismail and King (2007) four-dimensions of IT sophistication to compute the sample firms' degree of sophistication with IT. Each dimension is discussed separately below.

Table 2 summarizes the technological sophistication of the aligned and not-aligned groups by showing the percentage of each group that reported using each of the nine specific technologies.

\section{Table 2}

Alignment groups and technological sophistication

\begin{tabular}{llcl}
\hline Technological sophistication & igned(125) & Not-aligned (149) & sig \\
\hline Technology (\% of group indicating use): & & & 74 \\
Office support system & 65 & 68 & .372 \\
Decision support system & 52 & 88 & .102 \\
Database system & 95 & 40 & .056 \\
Accounting application & 45 & 35 & .256 \\
Computer-assisted production management & 30 & 18 & .312 \\
Computer-aided design & 20 & 70 & .360 \\
Computer-aided manufacturing & 60 & 5.20 & .253 \\
Local area network & 5.4 & & .856 \\
External network & & & \\
Number of technologies used & & & \\
\hline
\end{tabular}


Table 3 shows the informational sophistication of the aligned and not-aligned groups where the number of applications applied in each firm were totaled, and then averaged over each group so that an independent-sample t-test could be performed on the difference of means.

Table 3

Alignment groups and informational sophistication

\begin{tabular}{lccc}
\hline Technological sophistication & Aligned (125) & Not-aligned (149) & Sig \\
Applications (\% of group indicating use): & & 86 & .050 \\
\hline General ledge & 90 & 88 & .065 \\
Accounts receivable & 92 & 65 & .404 \\
Accounts payable & 90 & 54 & .072 \\
Billing & 75 & 60 & .521 \\
Purchasing & 55 & 18 & .080 \\
Inventory & 70 & 30 & .320 \\
Production planning & 22 & 55 & .220 \\
Cost accounting & 37 & 21 & .545 \\
Financial accounting & 56 & 24 & .003 \\
Financial analysis & 40 & 10 & .060 \\
Budgeting & 36 & 12 & .008 \\
Project management & 20 & 14 & .135 \\
Production variances & 18 & 10 & .005 \\
Budget variances & 22 & 2 & .003 \\
Modeling & 10 & 9.20 & .006 \\
Number of applications used & 10.25 & & \\
\hline
\end{tabular}

\subsubsection{Owner/manager knowledge and AIS alignment}

According to the results of Table 4, owners/managers in the sample SMEs believe they possess a good knowledge of e-mail and Internet and their knowledge of email and the Internet was somehow higher than other IT applications. An independent-samples t-test was then applied to investigate the relationship between alignment groups and knowledge variables. The results indicate that only the owner/manager's knowledge of more sophisticated software contributes to AIS alignment. Other software packages did not differ between the two alignment groups. The reason could be because most businesses, including SMEs, were expected to have knowledge in common applications such as word processing and spreadsheets. The implementation of e-mail and the Internet has been becoming more of a business necessity for SMEs.

Table 4

Alignment groups and owner/manager knowledge

\begin{tabular}{lccc}
\hline Owner/Manager knowledge & Aligned (125) & Not-aligned (149) & Sig \\
\hline Word processing & 2.780 & 2.80 & .145 \\
Spreadsheet & 2.70 & 2.75 & .320 \\
Database & 2.30 & 2.35 & .050 \\
Accounting applications & 2.60 & 2.50 & .012 \\
Internet & 3.10 & 3.06 & .220 \\
E-mail & 3.20 & 3.10 & .780 \\
\hline
\end{tabular}

\subsubsection{Owner/manager commitment and AIS alignment}

The results of Table 5 demonstrate that the level of owners/managers' participation in information system implementation was significantly large in both alignment groups. Nevertheless, the results of an independent-samples t-test indicate very little support for the association between AIS alignment and owner/manager participation. 
Table 5

Alignment groups and owner/manager commitment

\begin{tabular}{lccc}
\hline Owner/manager commitment & Aligned (125) & Not-aligned (149) & Sig \\
\hline Information requirements & 3.20 & 3.40 & .221 \\
Choice of hardware and software & 3.01 & 3.20 & .270 \\
System implementation & 3.25 & 3.12 & .530 \\
Solving problems & 3.40 & 3.05 & .004 \\
Future plans & 3.50 & 3.40 & .387 \\
\hline
\end{tabular}

\subsubsection{Firm size and AIS alignment}

This study has used the number of employees as a surrogate measure for firm size. An independent sample t-test was performed to examine the impact of firm size on AIS alignment. Surprisingly, whilst the result indicates a significant difference $(\mathrm{F}=8.125 ; \mathrm{df}=225 ; \mathrm{p}=0.05)$ between the mean of employees of these two groups, the average number of employees for the aligned group is lower than the average number of employees for the not-aligned group. This unexpected result is consistent with Morikawa (2004) who reported that the relationship between IT and firm performance was positively significant only for small firms but not medium sized firms.

\section{Research Results and Discussion}

This paper has performed an empirical investigation on the alignment between AIS requirements, AIS capacities, and the factors impacting the alignment. The results of the moderation approach to measure fit have stated varying degrees of alignment across the nineteen accounting information characteristics.

This study has detected some support for Hypothesis 1, which proposed an association between AIS alignment and different characteristics of both technological sophistication and informational sophistication. The results have provided significant support for the relationship between informational sophistication and AIS alignment but not between technological sophistication and AIS alignment.

The results have provided support for the second hypothesis, which proposed a relationship between owner/manager IT and accounting knowledge with AIS alignment. Owner/manager knowledge of accounting was bigger in the aligned firms than less aligned firms. This provides some knowledge about both financial and managerial accounting for AIS alignment.

There was, however, very little support for the third hypothesis, which proposed a relationship between owner/manager commitment and AIS alignment. Commitment was measured based on the level of the owner/manager's participation in IT projects. Finally, results of this study did not find support for the fourth hypothesis, which postulated that larger firms could achieve better alignment than smaller firms would.

\section{Acknowledgement}

The authors would like to thank the anonymous referees for constructive comments on earlier version of this paper.

\section{References}

Adekoya, A. A., Eyob, E., Ikem, F. M., Omojokun, E. O., Quaye, A. M., \& Bada, A. O. (2005). Dynamics of information technology (IT) successful implementation in development countries: A Nigerian case study. Journal of Computer Information Systems, 45(3), 107-112.

Bergeron, F., Raymond, L., \& Rivard, S. (2001). Fit in strategic information technology management research: an empirical comparison of perspectives. Omega, 29(2), 125-142. 
Breen, J., \& Sciulli, N. (2002). Use of computerized record keeping in small business. Small Business Research Unit, Victoria University.

Chan, Y. E., Huff, S. L., Barclay, D. W., \& Copeland, D. G. (1997). Business strategic orientation, information systems strategic orientation, and strategic alignment. Information systems research, 8(2), 125-150.

Chang, C. H., \& Lee, C. W. J. (1992). Information acquisition as business strategy. Southern Economic Journal, 58(3), 750-761.

Chenhall, R. H., \& Morris, D. (1986). The impact of structure, environment, and interdependence on the perceived usefulness of management accounting systems. Accounting Review, 61(1), 16-35.

Chong, V. K., \& Chong, K. M. (1997). Strategic choices, environmental uncertainty and SBU performance: a note on the intervening role of management accounting systems. Accounting and Business Research, 27(4), 268-276.

Cragg, P., King, M., \& Hussin, H. (2002). IT alignment and firm performance in small manufacturing firms. The Journal of Strategic Information Systems, 11(2), 109-132.

Gul, F. A. (1991). The effects of management accounting systems and environmental uncertainty on small business managers' performance. Accounting and Business Research, 22(85), 57-61.

Gul, F. A., \& Chia, Y. M. (1994). The effects of management accounting systems, perceived environmental uncertainty and decentralization on managerial performance: a test of three-way interaction. Accounting, Organizations and Society, 19(4), 413-426.

Hartcher, J. (2003). Small Business Survey Program: Financial Management. Insolvency and Fraud, CPA Australia.

Igbaria, M., Zinatelli, N., Cragg, P., \& Cavaye, A. L. (1997). Personal computing acceptance factors in small firms: a structural equation model. MIS Quarterly, 279-305.

Ismail, N. A., \& King, M. (2005). Firm performance and AIS alignment in Malaysian SMEs. International Journal of Accounting Information Systems, 6(4), 241-259.

Ismail, N.A., \& King, M. (2007). Factors influencing the alignment of accounting information

systems in small and medium sized Malaysian manufacturing firms. Journal of Information Systems and Small Business, 2(1-2), 1-20.

Ismail, N. A., Abdullah, S. N., \& Tayib, M. (2012). Computer-based accounting systems: the case of manufacturing-based small and medium enterprises in the Northern Region of Peninsular Malaysia. Jurnal Teknologi, 39(1), 19-36.

Jarvenpaa, S. L., \& Ives, B. (1991). Executive involvement and participation in the management of information technology. MIS quarterly, 15(2), 205-227.

Ortiz de Guinea, A., Kelley, H., \& Hunter, M. G. (2005). Information systems effectiveness in small businesses: extending a Singaporean model in Canada. Journal of Global Information Management (JGIM), 13(3), 55-79.

Sian, S., \& Roberts, C. (2006). Micro-entity financial reporting: Perspectives of preparers and users. Information Paper, IFAC Small and Medium Practices Committee, New York, NY, December.

Thong, J. Y., Yap, C. S., \& Raman, K. S. (1996). Top management support, external expertise and information systems implementation in small businesses. Information systems research, 7(2), 248267.

Thong, J. Y. (1999). An integrated model of information systems adoption in small businesses. Journal of management information systems, 15(4), 187-214.

Thong, J. Y. (2001). Resource constraints and information systems implementation in Singaporean small businesses. Omega, 29(2), 143-156.

Van de Ven, A.H., \& Drazin, R. (1985). The concept of fit in contingency theory. Research in Organizational Behavior, 7, 333-365.

Venkatraman, N. (1989). The concept of fit in strategy research: toward verbal and statistical correspondence. Academy of Management Review, 14(3), 423-444.

Weill, P., \& Olson, M. H. (1989). An assessment of the contingency theory of management information systems. Journal of Management Information Systems, 6(1), 59-79. 
Winston, E. R., \& Dologite, D. G. (1999). Achieving IT infusion: A conceptual model for small businesses. Information Resources Management Journal (IRMJ), 12(1), 26-38.

Yap, C. S., \& Thong, J. Y. (1997). Programme evaluation of a government information technology programme for small businesses. Journal of Information Technology, 12(2), 107-120.

Zarowin, S. (1998). Accounting software: The road ahead. Journal of Accountancy, 185, 67-70. 